\title{
CHANGES IN EVENTS and
}

\section{CHANGES IN THINGS}

by

\section{A. N. PRIOR}

Professor of Philosophy, University of Manchester

The Lindley Lecture

University of Kansas

1962 
Copyright Department of Philosophy,

University of Kansas, Lawrence, Kansas.

Address inquiries to the Chairman. 


\section{CHANGES IN EVENTS}

\section{and \\ CHANGES IN THINGS \\ by}

A. N. Prior

THE BASIC QUESTION to which I wish to address myself in this
lecture is simply the old one, Does time really flow or pass? The
problem, of course, is that genuine flowing or passage is some-
thing which occurs in time, and takes time to occur. If time itself
flows or passes, must there not be some super-time' in which it
does so? Again, whatever flows or passes does so at some rate,
but a rate of flow is just the amount of movement in a given
time, so how could there be a rate of flow of time itself? And if
times does not flow at any rate, how can it flow at all?
A natural first move towards extricating ourselves from these
perplexities is to admit that talk of the flow or passage of time is
just a metaphor. Time may be, as Isaac Watts says, like an ever-
rolling stream, but it isn't really and literally an ever-rolling
stream. But bow is it like an ever-rolling stream? What is the
literal truth behind this metaphor? The answer to this is not, at
first sight, difficult. Generally when we make such remarks as
"Time does fly, doesn't it? - why, it's already the 16th," we mean
that some date or moment which we have been looking forward
to as future, has ceased to be future and is now present and on
its way into the past. Or more fundamentally, perhaps, some
future event to which we have been looking forward with hope
or dread is now at last occurring, and soon will have occurred, 
and will have occurred a longer and longer time ago. We might say, e.g. "Times does fly-I'm already 47"- that is, my birth is already that much past, "and soon I shall be 48 ," i.e. it will be more past still. Suppose we speak about something "becoming more past" not only when it moves from the comparatively near past to the comparatively distant past, but also when it moves from the present to the past, from the future to the present, and from the comparatively distant future to the comparatively near future. Then whatever is happening, has happened or will hap. pen is all the time "becoming more past" in this extended sense; and just this is what we mean by the flow or passage of time. And if we want to give the rate of this flow or passage, it is surely very simple-it takes one exactly a year to get a year older. i.e. events become more past at the rate of a year per year, an hour per hour, a second per second.

Does this remove the difficulty? It is far from obvious that it does. It's not just that an hour per hour is a queer sort of rate -this queerness, I think, has been exaggerated, and I shall say more about it in a minute- but the whole idea of events changing is at first sight a little strange, even if we abandon the admittedly figurative description of this change as a movement. By and large, to judge by the way that we ordinarily talk, it's things that change, and events don't change but bappen. Chairs, tables, horses, people change-chairs get worn out and then mended, tables get dirty and then clean again, horses get tired and then refreshed, people learn things and forget them, or are happy and then miserable, active and then sleepy, and so on, and all these are changes, and chairs, tables, horses and people are all what I mean by things as opposed to events. An accident. a coronation, a death, a prizegiving, are examples of what we'd call events, and it does seem unnatural to describe these as changing - what these do, one is inclined to say, is not to change but to happen or occur.

One of the things that makes us inclined to deny that events undergo changes is that events are changes-to say that such and such an event has occurred is generally to say that some thing has, or some things have, changed in some way. To say, for instance, that the retirement of Sir Anthony Eden occurred in such and such a year is just to say that Sir Anthony then retired and so suffered the change or changes that retirement consists in -he had been Prime Minister, and then was not Prime Minister. 
Sir Anthony's retirement is or was a change concerning Sir Anthony; to say that it itself changes or has changed sounds queer because it sounds queer to talk of a change changing.

This queerness, however, is superficial. When we reflect further we realize that changes do change, especially if they go on for any length of time. (In this case we generally, though not always, call the change a process rather than an event, and there are other important differences between events and processes beside the length of time they take, but these differences are not relevant to the present discussion, so I shall ignore them and discuss changes generally, events and processes alike). Changes do change-a movement, for example, may be slow at first and then rapid, a prizegiving or a lecture may be at first dull and afterwards interesting, or vice versa, and so on. It would hardly be too much to say that modern science began when people became accustomed to the idea of changes changing, e.g. to the idea of acceleration as opposed to simple motion. I've no doubt the ordinary measure of acceleration, so many feet per second per second, sounded queer when it was first used, and I think it still sounds queer to most students when they first encounter it. Ordinary speech is still resistant to it, and indeed to the expression of anything in the nature of a comparison of a comparison. We are taught at school that "more older," for example, is bad English, but why shouldn't I say that I am more older than my son than he is than my daughter? And if we have learned to talk of an acceleration of a foot per second per second without imagining that the second 'second' must somehow be a different kind of 'second' from the first one-without imagining that if motion takes place in ordinary time, acceleration must take place in some super-time-can we not accustom ourselves equally to a change of "a second per second" without any such imagining?

Changes do change, then, but this does not leave everything quite simple and solved. For there's still something odd about the change that we describe figuratively as the flow or passage of time-the change from an event's being future to its being present, and from its being present to its being more and more past. For the other changes in events which $I$ have mentioned are ones which go on in the event wbile it is occurring; for example, if a lecture gets duller or a movement faster then this is something it does as it goes on; but the change from past to still further past isn't one that occurs while the event is occurring, 
for all the time that an event is occurring it isn't past but present, in fact the presentness of an event just is its happening, its occurring, as opposed to its merely having happened or being merely about to happen. We might put it this way: the things that change are existing things, and it's while they exist that they change, e.g. it's existing men, not non-existent men, that get tired and then pick up again; Julius Caesar, for example, isn't now getting tired and picking up again, unless the doctrine of immortality is true and he exists now as much as he ever did. And such changes as the change in the rate of movement are similarly changes that go on in events or processes while they exist, that is, while they exist in the only sense in which events and processes do exist, namely while they are occurring. But getting more and more past seems to be something an event does when it doesn't exist, and this seems very queer indeed.

We may retrace our steps to this point by looking at some of the literature of our subject. Professor C. D. Broad, in the second volume of his Examination of McTaggart's Pbilosopby, says that the ordinary view that an event, say the death of Queen Anne, is in the indefinitely distant future and then less and less future and then present and then goes into the more and more distant past-this ordinary story, Broad says, cannot possibly be true because it takes the death of Queen Anne to be at once a mere momentary thing and something with an indefinitely long history. We can make a first answer to this by distinguishing between the history that an event has, and the bit of history that it is. The bit of history that Queen Anne's death is, or was, is a very very short bit, but that doesn't prevent the history that it has from being indefinitely long. Queen Anne's death is part of the history of Queen Anne, and a very short part of it; what is long is not this part of the history of Queen Anne, but rather the history of this part of her history-the history of this part of her history is that first it was future, then it was present, and so on, and this can be a long history even if the bit of history that it is the history of is very short. There is not, therefore, the flat contradiction that Broad suggests here. There is, however, the difficulty that we generally think of the history of a thing as the sum of what it does and what happens to it while it is therewhen it ceases to be, its history has ended-and this does make it seem odd that there should be an indefinitely long history of something which itself occupies a time which is indefinitely short. 
But if there is a genuine puzzle here, it concerns what is actually going on also. For whatever goes on for any length of time -and that means: whatever goes on-will have future and past phases as well as the immediately present one; its going on is in fact a continual passage of one phase after another from being future through being present to being past. Augustine's reflections, in the eleventh chapter of his Confessions, on the notion of a "long time," are relevant here. Just when, he asks, is a long time long? Is it long when it is present, or when it is past or future? We need not, I think, attach much importance to the fact that Augustine concentrates on so abstract a thing as a "time" or an interval; his problems can be quite easily re-stated in terms of what goes on over the interval; in fact he himself slips into this, and talks about his childhood, a future sunrise and so on. When, we may ask, does a process go on for a long time-while it is going on, or when it lies ahead of us, or is all over?

Augustine is at first driven to the view that it is when it is present that a time is long, for only what is can be long or short (paragraph 18). We can give the same answer with processesit is when they are going on that they go on for a long time. But then, as Augustine points out, there are these phases. A hundred years is a long time, but it's not really present all at once, and even if we try to boil down the present to an hour, "that one hour passes away in flying particles." "The present hath no space" (20). Augustine had apparently not heard of the "specious present," but even if he had it would not have helped him much-most of the happenings we are interested in take longer than that. He tries out the hypothesis that the past and the future, and past and future events, in some sense after all "are" -that there is some "secret place" where they exist all the time, and from which they come and to which they go. If there is no such place, then where do those who foresee the future and recall the past, discern these things? "For that which is not, cannot be seen" (22).

Well, Augustine says, he doesn't know anything about that, but one thing that he does know is that wherever "time past and to come" may "be," "they are not there as future, or past, but present. For if there also they be future, they are not yet there: if there also they be past, they are no longer there. Wheresoever then is whatsoever is, it is only as present" (23). Of course there are present "traces" or images of past things in our mem. 
ories, and present signs and intentions on the basis of which we make our future forecasts $(23,24)$, and sometimes Augustine seems satisfied with this-past, present and future, he says "do exist in some sort, in the soul, but otherwhere do I not see them" (26). But sometimes he seems far from content with this-that which we remember and anticipate, he says, is different from these signs, and is not present $(23,24)$-and, one must surely add, is not "in the soul."

It is time now to be constructive, and as a preparation for this I shall indulge in what may seem a digression, on the subject of Grammar. English philosophers who visit the United States are always asked sooner or later whether they are "analysts." I'm not at all sure what the answer is in my own case, but there's another word that Professor Passmore once invented to describe some English philosophers who are often called "analysts," namely the word "grammaticist," and that's something I wouldn't at all mind calling myself. I don't deny that there are genuine metaphysical problems, but I think you have to talk about grammar at least a little bit in order to solve most of them. And in particular, I would want to maintain that most of the present group of problems about time and change, though not quite all of them, arise from the fact that many expressions which look like nouns, i.e. names of objects, are not really nouns at all but concealed verbs, and many expressions which look like verbs are not really verbs but concealed conjunctions and adverbs. That is a slight over-simplification, but before we can get it stated more accurately we must look more closely at verbs, conjunctions and adverbs.

I shall assume that we are sufficiently clear for our present purposes as to what a noun or name is, and what a sentence is; and given these notions, we can define a verb or verb-phrase as an expression that constructs a sentence out of a name or names. For instance, if you tack the verb "died" on the name "Queen Anne" you get the sentence "Queen Anne died," and if you tack the phrase "is an undertaker" on the name "James Bowels" you get the sentence "James Bowels is an undertaker," so that this is a verb-phrase. I say. "out of a name or names" because some verbs have to have an object as well as a subject. Thus if you put the verb "loves" between the names "Richard" and "Joan" you get the sentence "Richard loves Joan"; this verb constructs this sentence out of these two names; and the phrase "is taller than" 
would function similarly. Logicians call verbs and verb-phrases "predicates"; "died" and "is an undertaker" would be "oneplace" predicates, and "loves" and "is taller than" are "twoplace" predicates. There are also expressions which construct sentences, not out of names, but out of other sentences. If an expression constructs a sentence out of two or more other sentences it is a conjunction, or a phrase equivalent to a conjunction. For example "Either-or-" functions in this way in "Either it will rain or it will snow." If the expression constructs a sentence out of one other sentence it is an adverb or adverbial phrase, like "not" or "It is not the case that," or "allegedly" or "It is alleged that," or "possibly" or "It is possible that." Thus by attaching these expressions to "It is raining" we obtain the sentences

It is not raining.

It is not the case that it is raining.

It is allegedly raining.

It is alleged that it is raining.

It is possibly raining.

It is possible that it is raining.

One very importance difference betwen conjunctions and adverbs on the one hand and verbs on the other is that because the former construct sentences out of sentences, i.e. the same sort of thing as they end up with, they can be applied again and again to build up more and more complicated sentences, like "It is allegedly possible that he will not come," which could be spread out as

It is said that (it is possible that (it is not the case that (he will come))).

You can also use the same adverb twice and obtain such things as double negation, alleged allegations and so on. Verbs, because they do not end up with the same sort of expression as what they start with, cannot be piled up in this way. Having constructed "Queen Anne died" by the verb "died" out of the name "Queen Anne," you cannot do it again-"Queen Anne died died" is not a sentence.

Turning now to our main subject, I want to suggest that putting a verb into the past or future tense is exactly the same sort of thing as adding an adverb to the sentence. "I was having my breakfast" is related to "I am having my breakfast" in exactly the same way as "I am allegedly having my breakfast" is related 
to it, and it is only a historical accident that we generally form the past tense by modifying the present tense, e.g. by changing "am" to "was," rather than by tacking on an adverb. In a rationalised language with uniform constructions for similar functions we could form the past tense by prefixing to a given sentence the phrase "It was the case that," or "It has been the case that" (depending on what sort of past we meant), and the future tense by prefixing "It will be the case that:" For example, instead of "I will be eating my breakfast" we could say

"It will be the case that I am eating my breakfast," and instead of "I was eating my breakfast" we could say.

"It was the case that I am eating my breakfast."

The nearest we get to the latter in ordinary English is "It was the case that I was eating my breakfast," but this is one of those anomalies like emphatic double negation. The construction I am sketching embodies the truth behind Augustine's suggestion of the "secret place" where past and future times "are," and his insistence that wherever they are, they are not there as past or future but as present. The past is not the present but it is the past present, and the future is not the present but it is the future present.

There is also, of course, the past future and the future past. For these adverbial phrases, like other adverbial phrases, can be applied repeatedly-the sentences to which they are attached do not have to be simple ones; it is enough that they be sentences. and they can be sentences which already have tense-adverbs, as we might call them, within them. Hence we can have such a construction as

"It will be the case that (it has been the case that

(I am taking off my coat)),"

or in plain English, "I will have taken off my coat." We can similarly apply repeatedly such specific tense-adverbs as "It was the case 48 years ago that." For example, we could have

"It will be the case 7 months hence that (it was the

case 48 years ago that (I am being born))," that is, it will be my 48th birthday in 7 months time.

To say that a change has occurred is to say at least this much: that something which was the case formerly is not the case now: That is, it is at least to say that for some sentence $p$ we have

It was the case that $p$, and it is not the case that $p$.

This sentence $p$ can be as complicated as you like, and can itself 
contain tense-adverbs, so that one example of our formula would be

It was the case 5 months ago that (it was the case only 47 years ago that ( $I$ am being born)), and it is not now the case that (it was the case only 47 years ago that (I am being born)),

that is, I am not as young as I used to be. This last change, of course, is a case of precisely that recession of events into the past that we are really talking about when we say that time flows or passes, and the piling of time-references on top of one another. with no suggestion that the time-words must be used in a different sense at each level, simply reflects the fact that tense-adverbs are adverbs, not verbs.

An important point to notice now is that while $I$ have been talking about words-for example about verbs and adverbsfor quite a long time, the sentences that $I$ have been using as examples have not been about words but about real things. When a sentence is formed out of another sentence or other sentences by means of an adverb or conjunction, it is not about those other sentences, but about whatever they are themselves about. For example, the compound sentence, "Either I will wear my cap or I will wear my beret" is not about the sentences "I will wear my cap" and "I will wear my beret"; like them, it is about me and my headgear, though the information it conveys about these is a little less definite than what either of them would convey separately. Similarly, the sentence "It will be the case that I am having my tooth out" is not about the sentence "I am having my tooth out"; it is about me. A genuine sentence about the sentence "I am having my tooth out" would be one stating that it contained 6 words and 19 letters, but "It will be the case that I am having my tooth out," i.c. "I will be having my tooth out," is quite obviously not a sentence of this sort at all.

Nor is it about some abstract entity named by the clause "that I am having my tooth out." It is about me and my tooth, and about nothing else whatever. The fact is that it is difficult for the human mind to get beyond the simple subject-predicate or noun-verb structure, and when a sentence or thought hasn't that structure but a more complex one we try in various ways to force it into the subject-predicate pattern. We thus invent new modes of speech in which the subordinate sentences are replaced by 
noun-phrases and the conjunctions or adverbs by verbs or verbphrases. For example, instead of saying

(a) If you have oranges in your larder you have been to the greengrocer's,

we may say

(b) Your having oranges in your larder implies your having been to the greengrocer's,

which looks as if it has the same form as "Richard loves Joan" except that "Your having oranges in your larder" and "Your having been to the grocer" seem to name more abstract objects than Richard and Joan, and implying seems a more abstract activity than loving. We can rid ourselves of this suggestion if we reflect that (b) is nothing more than a paraphrase of (a). Similarly,

(c) It is now 6 years since it was the case that I am falling out of a punt,

could be re-written as

(d) My falling out of a punt has receded 6 years into the past.

This suggests that something called an event, my falling out of a punt, has gone through a performance called receding into the past, and moreover has been going through this performance even after it has ceased to exist, i.e. after it has stopped happening. But of course (d) is just a paraphrase of (c), and like (c) is not about any objects except me and that punt-there is no real reason to believe in the existence either now or 6 years ago of a further object called "my falling out of a punt."

What I am suggesting is that what looks like talk about events is really at bottom talk about things, and that what looks like talk about changes in events is really just slightly more complicated talk about changes in things. This applies both to the changes that we say occur in events when they are going on, like the change in speed of a movement ("movement" is a facon de parler; there is just the moving car, which moves more quickly than it did), and the changes that we say occur in events when they are not going on any longer, or not yet, e.g. my birth's receding into the past ("birth" is a facon de parler-there's just me being born, and then getting older).

It's not all quite as simple as this, however. This story works very well for me and my birth and my fall out of the punt, but what about Queen Anne? Does Queen Anne's death getting more 
past mean that Queen Anne has changed from having died 150 years ago to having died 151 years ago, or whatever the period is? - that she is still "getting older," though in a slightly extended sense? The trouble with this, of course, is just that Queen Anne doesn't exist now any more than her death does. There are at least two different ways in which we might deal with this one. We might, in the first place, say that our statement really is about Queen Anne (despite the fact that she "is no more"), and really is, or at least entails, a statement of the form

It was the case that $p$, and is not now the case that namely $P$,

It was the case that it was the case only 150 years ago that Queen Anne is dying, and is not now the case that it was the case only 150 years ago that Queen Anne is dying,

but we may add that this statement does not record a "change" in any natural sense of that word, and certainly not a change in Queen Anne. A genuine record of change, we could say, must not only be of the form above indicated but must meet certain further conditions which we might specify in various ways. And we could say that although what is here recorded isn't a change in the proper sense, it is like a change in fitting the above formula. The flow of time, we would then say, is merely metaphorical, not only because what is meant by it isn't a genuine movement, but further because what is meant by it isn't a genuine change; but the force of the metaphor can still be explained-we use the metaphor because what we call the flow of time does fit the above formula. On this view it might be that not only the recession of Queen Anne's death but my own growing older will not count as a change in the strict sense, though growing older is normally accompanied by genuine changes, and the phrase is commonly extended to cover these-increasing wisdom, bald patches and so on.

But can a statement really be about Queen Anne after she has ceased to be? I do not wish to dogmatise about this, but an alternative solution is worth mentioning. We might paraphrase "Queen Anne has died" as "Once there was a person named 'Anne,' who reigned over England, etc., etc., but there is not now any such person." This solution exploits a distinction which we may describe as one between general facts and individual facts. 
That someone has stolen my pencil is a general fact; that John Jones has stolen my pencil, if it is a fact at all, is an individual fact. It has often been said-for example, it was said by the Stoic logicians-that there are no general facts without there being the corresponding individual facts. It cannot, for example, be the case that "someone" has stolen my pencil, unless it is the case that some specific individual-if not John Jones, then somebody else-has stolen it. And in cases of this sort the principle is very plausible, indeed it is obviously true. I have read that some of the Schoolmen described the subject of sentences like "someone has stolen my pencil" as an individuum vagum, but of course this is a makeshift-forcing things into a pattern again. There are no "vague individuals," and if a pencil has been stolen at all it has been stolen not by a vague individual but by some quite definite one, or else by a number of such. There are vague statements, however, and vague thoughts, and the existence of such statements and thoughts is as much a fact about the real world as any other; and when we describe the making of such statements and the entertaining of such thoughts, we do encounter at least partly general facts to which no wholly individual facts correspond. If I allege or believe that someone has stolen my pencil, there may be no specific individual with respect to whom I allege or believe that be stole my pencil. There is alleged or believed to be an individual who stole it, but there is no individual who is alleged or believed to have stolen it (not even a vague one). So while it is a fact that I allege or believe that someone stole it, there is no fact of the form "I allege (or believe) that X stole it." The one fact that there is, is no doubt an individual fact in so far as it concerns me, but is irreducibly general as far as the thief is concerned. (There may indeed be no thief-I am perhaps mistaken about the whole thing-but this is another question; our present point is that there may be no one who is even said or thought to be a thief, though it is said or thought that there is a thief).

Returning now to Queen Anne, what I am suggesting is that the sort of thing that we unquestionably do have with "It is said that" and "It is thought that," we also have with "It will be the case that" and "It was the case that." It was the case that someone was called "Anne," reigned over. England, etc., even though there is not now anyone of whom it was the case that she was called "Anne," reigned over England, etc. What we 
must be careful about here is simply getting our prefixes in the right order. Just as

does not imply

(a) I think that (for some specific X (X stole my pencil))

(b) For some specific X (I think that (X stole my pencil)),

so

(c) It was the case that (for some specific $\mathrm{X}$ ( $\mathrm{X}$ is called "Anne," reigns over England, etc.))

does not imply

(d) For some specific $\mathrm{X}$ (it was the case that ( $\mathrm{X}$ is called "Anne," reigns over England, etc)) .

On this view, the fact that Queen Anne has been dead for some years is not, in the strict sense of "about," a fact about Queen Anne; it is not a fact about anyone or anything-it is a general fact. Or if it is about anything, what it is about is not Queen Anne- it is about the earth, maybe, which has rolled around the sun so many times since there was a person who was called "Anne," reigned over England, etc. (It would then be a partly general fact-individual in so far as it concerns the earth, but irreducibly general as far as the dead queen is concerned. But if there are-as there undoubtedly are-irreducibly partly-general facts, could there not be irreducibly wholly-general ones?) Note, too, that the fact that this fact is not about Queen Anne, cannot itself be a fact about Queen Anne-its statement needs rephrasing in some such way as "There is no person who was called 'Anne,' etc., and about whom it is a fact that, etc."

On this view, the recession of Queen Anne's death into the further past is quite decidedly not a change in Queen Anne, not because we are using "change" in so tight a sense that it is not a change at all, but because Queen Anne doesn't herself enter into this recession, or indeed, now, into any fact whatever. But the recession is still a change or quasi-change in the sense that it fits the formula "It was the case that $p$, but is not now the case that $\mathrm{p}$ "- this formula continues to express what is common to the flow of a literal river on the one hand (where it was the case that such-and-such drops were at a certain place, and this is the case no longer) and the flow of time on the other. 